\title{
Role of Web Mining in E-Commerce
}

\author{
Arti $^{1}$, Sunita Choudhary ${ }^{2}$, G.N Purohit ${ }^{3}$ \\ Research Scholar, AIM \& ACT, Banasthali University, Rajasthan, India ${ }^{1}$ \\ Associate Professor, Computer Science, Banasthali University, Rajasthan, India ${ }^{2}$ \\ Professor, AIM \& ACT, Banasthali University, Rajasthan, India ${ }^{3}$
}

\begin{abstract}
E-commerce is all about carrying out business on the Web. It is about carrying out transactions, essentially buying and selling products and services by consumers and businesses respectively, on the web. Web is one of the largest sources of information, collection of many files stored in different web servers and its size is also growing rapidly. E-Commerce not only keep your business up and running but also make it tough to stand in the competitive world of e-business. E-commerce has provided a cost efficient and effective way of doing business in the web. Web mining is the application of data mining techniques to discover and extract useful and interesting information from the Web.
\end{abstract}

\section{Keywords: E-Commerce, Web Mining}

\section{INTRODUCTION}

Due to the rapid and drastic growth of the E-commerce, 3. In the business world, structure mining can be quite the way companies are doing businesses has been changed useful in determining the connection between two or more drastically. E-commerce that is mainly characterized by business Web sites.

doing business electronically with the help of the Internet 4. This allows accounting, customer profile, inventory, and has provided us a cost-efficient and effective way of doing demographic information to be correlated with Web business. Nowadays unfortunately, to most companies, browsing 5. The company can identify the strength and web is nothing more than a place where transactions take weakness of its web marketing campaign through Web place. All the ecommerce sites have high traffic. People Mining, and then make strategic adjustments, obtain the surf these sites very often but the income is not always feedback from Web Mining again to see the improvement. very high. So, the web data mining appeared and also 6. Search engine Google provides advanced and efficient nowadays much attention is paid to it. It is very important searching capabilities. [2]

to apply web data mining to ecommerce in order to gather Web mining is mainly divided into three categories: Web knowledge about users and rank data accordingly. Web content mining, Web structure mining and Web usage data mining is a branch of data mining. It is successful mining.

technology through which information is filtered easier. [1]

\section{Web Mining}

Web mining is applied to extract the interesting, useful patterns and hidden information from the Web documents and Web activities. Web mining simply refers to the discovery of information from Web data that include Web pages, media objects on the Web, Web links, Web log data, and other data generated by the usage of Web data. Web mining extends analysis much further by combining other corporate information with Web traffic data. Practical applications of Web mining technology are abundant, and are by no means the limit to this technology. Web mining tools can be extended and programmed to answer almost any question. It can be applied in following areas:

1. Web mining can provide companies managerial insight into visitor profiles, which help top management take strategic actions accordingly.

2. The company can obtain some subjective measurements through Web Mining on the effectiveness of their marketing campaign or marketing research, which will help the business to improve and align their marketing strategies timely.

Web Content Mining: Web Content Mining is the process of extracting useful information from the contents of Web documents. Content data corresponds to the collection of facts a Web page was designed to convey to the users. It may consist of text, images, audio, video, or structured records such as lists and tables. While there exists a significant body of work in extracting knowledge from images - in the fields of image processing and computer vision - the application of these techniques to Web content mining has not been very rapid. [3]

Web Structure Mining: The structure of a typical Web graph consists of Web pages as nodes, and hyperlinks as edges connecting between two related pages. Web Structure Mining can be regarded as the process of discovering structure information from the Web. This type of mining can be further divided into two kinds based on the kind of structural data used. [3]

Web Usage Mining: Web Usage Mining is the application of data mining techniques to discover interesting usage patterns from Web data, in order to understand and better serve the needs of Web-based applications. [3] 


\section{III.ISSUES OF WEB MINING IN E-COMMERCE}

There are some issues that need to be discussed in order to apply the web mining in e-commerce.

- Certain important implementation parameters in retail e-commerce sites like the automatic time outs of user sessions due to perceived inactivity at the user end need to be based not purely on data mining algorithms, but on the relative importance of the users to the organization. It should not turn out that large clients are made to lose their shopping carts due to the time outs that were fixed based on a data mining of the application logs.

- $\quad$ Generating $\operatorname{logs}$ for several million transactions is a costly exercise. It may be wise to generate appropriate logs by conducting random sampling, as is done in statistical quality control. But such a sampling may not capture rare events, and in some cases like in advertisement referral based compensations, the data capture may be mandatory. Techniques thus need to be in place that can do this sampling in an intelligent fashion.

- Designing user interface forms needs to consider the data mining issues in mind. For instance, disabling default values on various important attributes like Gender, Marital status, Employment status, etc., will result in richer data collected for demographical analysis. The users should be made to enter these values, since it has found that several users left the default values untouched.

- $\quad$ Mining data at the right level of granularity is essential .Otherwise, the results from the data mining exercise may not be correct.

- $\quad$ Collecting data at the right level of abstraction is very important. Web server logs were originally meant for debugging the server software. Hence they convey very little useful information on customer related transactions. Approaches including sessionising the web logs may yield better results. A preferred alternative would be having the application server itself log the user related activities. This is certainly going to be richer in semantics compared to the state-less web logs, and is easier to maintain compared to state-full web logs. [1]

\section{IV.APPLICATION OF WEB MINING IN E-COMMERCE}

The emergence of e-commerce has changed the traditional way of doing the business, also changed the relationship between the sellers and buyers. The expanded customer choice makes them pay more attention to the value of goods, but unlike the previous first consider the brand and geographical factors. Therefore, in terms of the seller to as much as possible understand customer's tastes and values can remain invincible in the competition. Data mining technology can effectively help sellers to understand customer behaviours and improve the efficiency of site, thus having been widely used in the e-commerce design, customer relationship management, internet marketing and other fields. Web mining develops examination much further by joining together other corporate data with Web movement information. Reasonable provisions of Web mining innovation are bounteous, and are in no way, shape or form the point of confinement to this engineering. Web mining devices could be stretched out and modified to answer very nearly any inquiry. It might be connected in taking after regions:

-Web mining can give organizations managerial understanding into guest profiles, which help top administration take key movements accordingly.

- The organization can acquire some subjective estimation through Web Mining on the adequacy of their promoting crusade or advertising examination, which will help the business to enhance and adjust their showcasing procedures auspicious.

- In the business world, structure mining could be very functional in deciding the association between two or more business Web destinations.

-This permits bookkeeping, client profile, stock, and demographic data to be associated with Web skimming.

- The organization can distinguish the quality and shortcoming of its web showcasing crusade through Web Mining, and afterward make vital conformities, get the criticism from Web Mining again to see the change.

- Web crawler Google gives progressed and proficient seeking capabilities [4]

\section{ROLE OF Web Mining In E-COMMERCE}

Financial Analyses: It includes reviewing of costs and revenues, calculation and comparative analysis of corporate income statements, analysis of corporate balance sheet and profitability, cash flow statement, analysis of financial markets and sophisticated controlling. Web mining can be an effective tool. [5]

Marketing Analyses: It includes analysis of sales receipts, sales profitability, profit margins, meeting sales targets, time of orders, actions undertaken by competitors, stock exchange quotations, and market identification and segmentation. Web mining can be used here as a key tools that helps in building effective marketing strategy. [5]

Customer Analysis: It mainly concern time maintaining contacts with customers, customer profitability, modelling customers' behaviour and reactions, customer satisfaction, churn analysis etc. web mining tells us what strategy should be used to get number of customers with quality.[5]

Production Management Analysis where work is mainly to identify production 'bottlenecks' and delayed orders and enabling organizations to examine production dynamics and to compare production results obtained by departments or plants, etc.[5]

Logistic Analysis where can be effective to identify partners of supply chain quickly, reverse logistics analysis and handling. [5]

Wage analysis where analysis of wage related data including wage component reports made with reference to the type required, reports made from the perspective of a given enterprise, wage report distinguishing employment types, payroll surcharges, personal contribution reports, analyse of average wages, etc. [5] 
Personal data analyses that includes examination of employment turnover, employment types, presentation of information on individual employee's personal data, etc. [5]

\section{Web Mining TOOLS IN E-COMMERCE}

Different data mining tools are used depending on different mining goals; there are major three categories that are statistic analysis, knowledge discovery, and prediction models.

1) Statistic analysis. This method is basically used to check the math rules in data and utilize statistic modes and math models to interpret these rules. There are some commonly used methods: linear and nonlinear analysis, continuous regression analysis and logistic regression analysis, univariate and multivariate analysis, and time series analysis. This method help to find the identification of time series data patterns and anomalies in the data to help select the appropriate statistical model and generate the appropriate charts, completed by the appropriate statistical tools regression analysis, and multivariate analysis.[5]

\section{2) Knowledge discovery}

Knowledge discovery is obtained from artificial intelligence and machine learning, which uses a datasearch process, to extract information from the data, as well as the relationship between data elements and models from which to discover business rules and business facts. In Knowledge discovery we can use data visualization tools and navigation tools to help developers analyse the data before mining, to further enhance data mining capabilities, visualization systems can be presented with a graphical analysis of multivariate data to help business analysts, knowledge discovery. [5]

\section{3) Prediction model}

Prediction model is based on consumer behaviour has a certain repetitive and regularity of such a hypothesis, which allows businesses to collect stored in the database $b$ analysing the transaction information to predict consumer behaviour. According to specific consumption behaviour to classify, businesses will be able to implement targeted marketing strategies. [5]

\section{CONCLUSION}

Web mining is applied to e-commerce to know the browsing behavior of customers, to determine the success of marketing efforts, to improve the design of e-commerce web site and to provide personalized services.

\section{REFERENCES}

[1] Ketul B. Patel, Jignesh A. Chauhan, Jigar D. Patel," Web Mining in E-Commerce: Pattern Discovery,Issues and Applications", International Journal of P2P Network Trends and TechnologyVolume1 Issue3-2011,ISSN: 2249-2615, Page 40.

[2]. Monika Yadav and Mr. Pradeep Mittal," Web Mining: An Introduction", International Journal of Advanced Research in Computer Science and Software Engineering, Volume 3, Issue 3, March 2013, ISSN: $2277128 \mathrm{X}$

[3]. Sonia Gupta and Neha Singh," Web Miining: Summary", International Journal of Computational Engineering Research, Volume 03,Issue 4,April 2013,Page 149
Mr. Akshay A. Adsod, Prof. Nitin R. Chopde," A Review on: Web Mining Techniques", International Journal of Engineering Trends and Technology (IJETT) - Volume 10 Number 3 - Apr 2014, ISSN: 2231-5381,Page 108.

[5] Jyoti Yadav, Bhawna Mallick," Web Mining: Characteristics and Application in Ecommerce", International Journal of Electronics and Computer Science Engineering, ISSN- 2277-1956, ISSN 2277 1956/V1N4-2020-2025. 